\title{
Homens de bem contra imagens do mal
}

\author{
Good Men Against Evil Images
}

\section{Hombres de bien contra imágenes del mal}

Thiago Spíndola Motta Fernandes

http://dx.doi.org/10.22409/poiesis.2033.395-412

\begin{abstract}
RESUMO: A tentativa de interdição, por grupos cristãos, a uma intervenção urbana do artista Alexandre Vogler, bem como a perseguição pela polícia e por civis a trabalhos artísticos de Guga Ferraz, levanta discussões sobre a destruição de imagens e a potência a elas atribuída pelo olhar de quem as nega e as destrói. A partir de teóricos como Jacques Rancière, W. J. T. Michell, Marie-José Mondzain e Hans Belting, entende-se que o ato de negar uma imagem pode ser um ato de afirmação de seu poder, bem como uma tentativa de interromper a busca icônica do outro e tomar para si a exclusividade e benefícios da imagem.

PALAVRAS-CHAVE: iconoclastia; intervenção urbana; arte contemporânea; imagem e poder
\end{abstract}

\footnotetext{
* Thiago Spíndola Motta Fernandes é historiador da arte e mestre em Artes Visuais pelo PPGAV-EBA-UFRJ. E-mail: thiagosmfernandes@gmail.com. Orcid: https://orcid.org/0000-0001-9008-5447
} 
ABSTRACT: The attempted interdiction by Christian groups of an urban intervention by Alexandre Vogler, as well as the persecution by police and civilians of Guga Ferraz's art works, raises discussions about the destruction of images and the power attributed to them by the eyes of who deny and destroy them. Based in theorists such as Jacques Rancière, W.J.T. Michell, Marie-José Mondzain and Hans Belting, it is understood that the act of denying an image can be an act of affirmation of its power, as well as an attempt to stop the iconic representation of the other and take on the exclusivity and benefits of the image.

KEYWORDS: iconoclasm; urban intervention; contemporary art; image and power

RESUMEN: El intento de interdicto, por cristianos, a una intervención urbana del artista Alexandre Vogler, así como la persecución por la policía y por civiles a trabajos artísticos de Guga Ferraz, levanta discusiones sobre la destrucción de imágenes y la potencia a ellas atribuida por los ojos de quien las niega y las destruye. A partir de teóricos como Jacques Rancière, W.J.T. Michell, Marie-José Mondzain y Hans Belting, se entiende que el acto de negar una imagen puede ser un acto de afirmación de su poder, así como un intento de interrumpir la búsqueda icónica del otro y tomar para sí la exclusividad y los beneficios de la imagen.

PALABRAS CLAVE: iconoclastia; intervención urbana; arte contemporáneo; imagen y poder 2019.

doi: http://dx.doi.org/10.22409/poiesis.2033.395-412 


\section{Homens de bem contra imagens do mal}

No dia 15 de agosto de 2006, a capa do jornal Meia-Hora denunciava um ato pecaminoso: "Prefeito de N. Iguaçu permite símbolo do inferno ao lado da cruz de Jesus Cristo". Tal era a chamada da matéria sobre o tridente que havia sido desenhado com cal no Morro do Cruzeiro, alguns metros acima de onde estava instalada uma cruz, principal símbolo do cristianismo. A intervenção é obra de Alexandre Vogler e fazia parte do Projeto Interferências Urbanas, promovido pela prefeitura de Nova Iguaçu, município da Baixada Fluminense. Contudo, havia sido autorizado outro projeto elaborado pelo artista, que escreveria sobre o morro a frase "Eu amo Nova Iguaçu". A mudança na proposta sem aviso prévio causou revolta entre moradores, religiosos e o então prefeito Lindberg Farias, que em uma matéria publicada no jornal O Dia condena a ação de Vogler:

Quando soube que tinha sido desenhado um tridente mandei retirar imediatamente. Ele tinha combinado de escrever "Eu Amo Nova Iguaçu". Mas acabou colocando esse símbolo que afronta a cruz. Desde pequeno que eu vejo a figura do diabo com tridente na mão. Moramos numa cidade de Deus. (JORNAL 0 DIA, 15 de agosto de 2006, p. 4) 


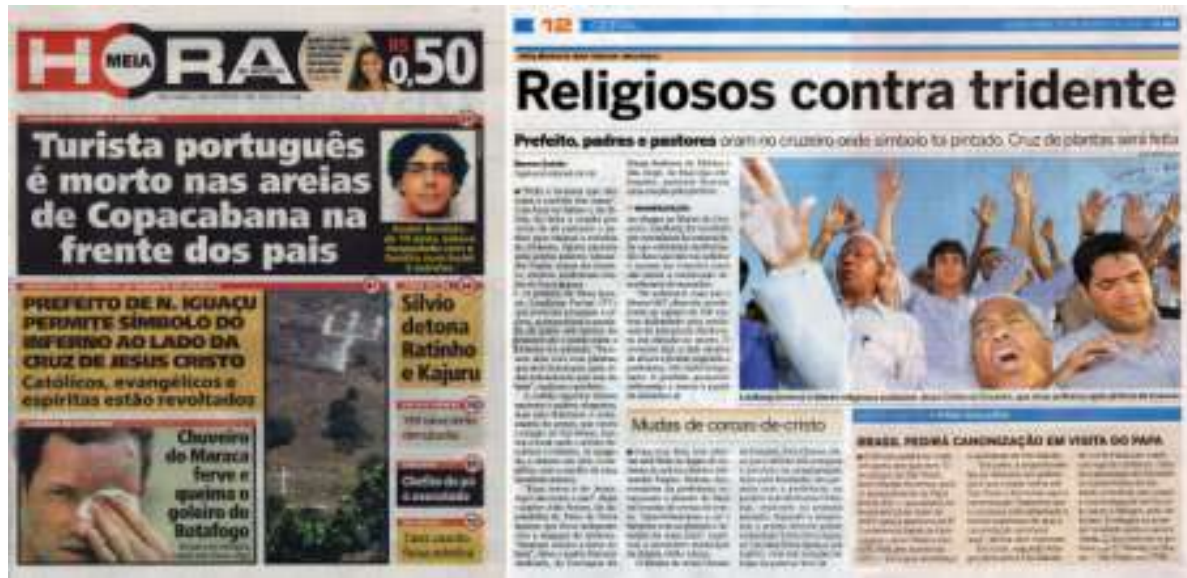

Fig. 1 - Jornais Meia-Hora (15 de agosto de 2006) e O Dia (17 de agosto de 2006) (Fonte: Arquivo de Alexandre Vogler)

Poiésis, Niterói, v. 20, n. 33, jan./jun. 2019. 
A polêmica rendeu ainda outras matérias em jornais. No dia 17 de agosto, o jornal O Dia noticiou a oração feita por cerca de 40 pastores e padres para marcar a retirada do tridente. Uma fotografia apresenta o então prefeito no meio dos líderes religiosos, com os braços erguidos, exorcizando o "símbolo do diabo" durante a ação que incluía o canto de um hino evangélico com apoio de uma banda musical.

No dia 22 de agosto, era anunciada no jornal a destruição do tridente. Aquela "cidade de Deus" estava finalmente livre do símbolo demoníaco. Embora a causa tenha sido um temporal que provocou sérios estragos em todo o estado do Rio de Janeiro, destruindo edificações e desabrigando centenas de moradores, líderes religiosos afirmavam que a tempestade fora uma resposta divina. A chuva teria sido enviada para apagar o desenho do mal graças às orações feitas pelos homens de bem.

O tridente pode remeter a diversos significados e entidades em diferentes culturas e mitologias. Vogler, em tentativa de apaziguamento após a tensão causada pela intervenção, o associa a Netuno, deus dos mares de acordo com a mitologia romana (correspondente a Poseidon na mitologia grega) e de quem a iconografia do diabo, no contexto do cristianismo, herda a figura do tridente como sobrevivência de um imaginário pagão. 0 cristianismo, por sua vez, proporciona o encontro do tridente com as religiões afro-brasileiras, que o incorporam na iconografia de Exu. Tal associação se dá pelo processo de sincretismo religioso, consequente da perseguição de todas formas de cultura material e imaterial de origem africana pela igreja católica, que impusera sua hegemonia sobre o Brasil.

Se por um lado a intervenção de Vogler foi condenada por cristãos, representantes da Umbanda e do Candomblé Ihe foram receptivos, demonstrando apoio ao artista. Embora as religiões de matriz africana tenham representação numerosa em Nova Iguaçu, seu culto é perseguido por evangélicos, assumindo dimensão quase de clandestinidade. (AMARO, 2009) Tal dado aponta para mais um fator que determina o interdito à intervenção de Vogler, pois, além de incorporar um signo que pode ser associado ao diabo, ele também possui relação com religiões que são confrontadas e demonizadas por cristãos, que correspondem à maior parte da população do município.

Poiésis, Niterói, v. 20, n. 33, jan./jun. 2018. 


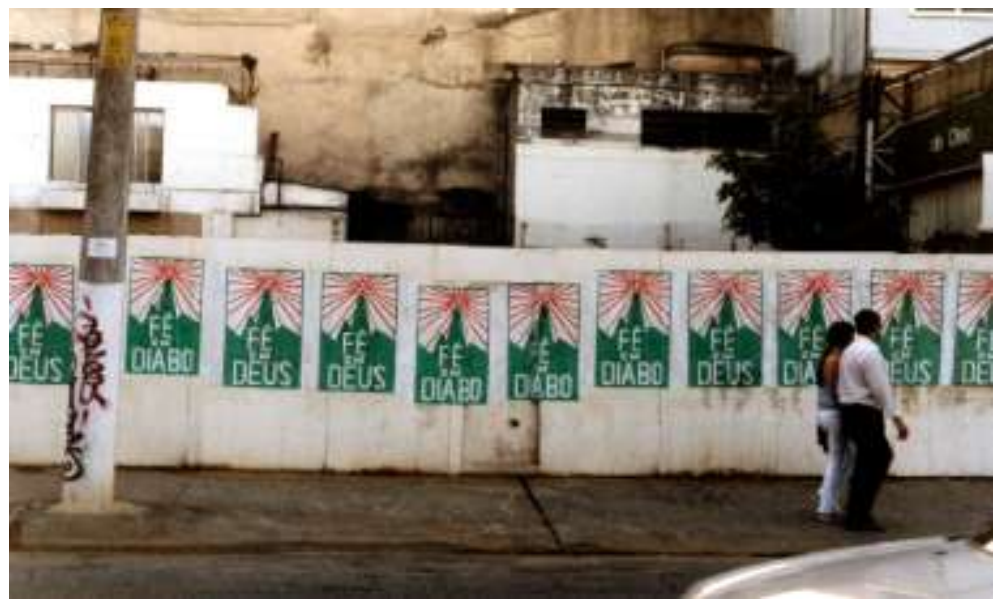

Fig. 2 - Alexandre Vogler, Fé em Deus - Fé em Diabo, 2001

cartazes lambe-lambe no tapume da Assembleia de Deus - Ministério de Belém, São Paulo (Fonte: arquivo do artista)

Poiésis, Niterói, v. 20, n. 33, jan./jun. 2019. 
Ao ganhar espaço nos jornais, a intervenção de Vogler colocou em evidência a intolerância religiosa presente em Nova Iguaçu, onde frequentemente terreiros são depredados por grupos evangélicos. O artista lançou uma provocação no espaço público e, em seguida, discursos intolerantes se disseminaram na mídia sem sua intervenção direta. O trabaIho continuou reverberando, ele ecoou nas folhas dos jornais, tomou a mídia de massa como espaço performativo, mas sem qualquer necessidade de ação do autor, que apenas assistiu a seu trabalho se desdobrar.

O artista já havia lançado uma provocação de natureza similar em 2001, quando colou em ruas de São Paulo, que incluía o tapume de uma igreja evangélica, cartazes com o slogan "Fé em Deus", que ora alternavam com a frase "Fé em Diabo". Em um jogo de informação e contrainformação, Vogler justapõe repetidamente uma frase já enraizada no cotidiano da cidade (Fé em Deus) e cria um ruído com outra inscrição (Fé em Diabo). Duas informações que, contudo, não deveriam soar contraditórias, considerando o dualismo cristão céu/inferno, quem crê em Deus, consequentemente, crê na existência do Diabo. A palavra "fé", no entanto, confunde-se com a ideia de culto ou compromisso, o que amplifica o ruído e o incômodo causado pelo artista.

Tal dado sugere que, embora o artista afirme em entrevistas cedidas a jornais que associava o tridente ao deus Netuno e não tinha a intenção de afrontar qualquer religião, havia, na verdade, consciência sobre as possíveis interpretações acerca de seu trabalho.

A negação da intervenção e sua consequente destruição por grupos cristãos acaba por reforçar sua potência. Jacques Rancière, no texto As imagens querem realmente viver?, afirma que "o iconoclasta quer preservar os outros desse perigo de que ele supõe, ele mesmo, preservado". (RANCIÈRE, 2015, p. 196) Segundo o filósofo francês, não haveria diferença entre denunciar a potência das imagens ou negá-las, pois "os dois atos expressam a mesma ansiedade diante de sua potência, o mesmo reconhecimento dessa potência". (RANCIÈRE, 2015, p. 196) No artigo em questão, Rancière parte de leituras do teórico norte-americano W. J. T. Mitchell, que coloca a imagem no papel de sujeito ao questionar $O$ que as imagens realmente querem?, título de seu artigo publicado em 1996 na revista October. 
Mitchell considera que estamos presos a atitudes mágicas e pré-modernas diante de objetos e, em particular, diante de imagens. Uma aura Ihes é atribuída. Até mesmo historiadores da arte, com plena consciência de que estudam objetos materiais marcados por cores e formas, "falam e agem como se as imagens tivessem sentimentos, vontade, consciência, agência e desejo". (MITCHELL, 2015, p. 168).

\section{Todos sabem que uma foto de sua mãe não é algo vivo, mas relutariam em destruí-la. Nenhum indivíduo moderno, racional e secular considera que imagens devem ser tratadas como pessoas, mas sempre dis- pomos a fazer algumas exceções em casos especiais. (MITCHELL, 2015, p. 168-169)}

Mitchell pondera que essa atitude não se restringe a obras de arte ou imagens de valor afetivo, pois executivos da publicidade têm consciência de que as imagens "têm pernas", ou seja, têm a capacidade de gerar novas direções e torções em campanhas, como se tivessem vontade própria.

Quando Moisés pede a Aarão que explique como fez o bezerro de ouro, Aarão responde que simplesmente jogou 0 ouro dos israelitas no fogo e "saiu este bezerro" como se fosse um autômato autogerado. Evidentemente alguns ídolos também "têm pernas". A ideia de que imagens têm um poder social e psicológico próprio é, de fato, o clichê reinante nos estudos contemporâneos em cultura visual. A alegação de que vivemos em uma sociedade do espetáculo, vigilância e simulacro não é mera intuição da crítica cultural. (MITCHELL, 2015, p. 160)

Vemos, a partir das ideias de Mitchell, duas questões centrais na intervenção de Vogler: uma é o valor mágico (e demoníaco) atribuído pelo olhar de cristãos. Outra é sua capacidade de, por si só, gerar diferentes interpretações e invadir o espaço da mídia de massa, que Ihe atribui determinado direcionamento conceitual, no qual o artista não possui mais controle sobre o discurso acerca da imagem que ele mesmo gerou.

Tal descontrole acerca do direcionamento conceitual da imagem se apresenta em intervenções urbanas de outro artista carioca: Guga Ferraz. Um exemplo é Dormindo (2006), lambe-lambe com uma fotografia do próprio artista em tamanho real, deitado no chão, que já foi instalado em diferentes cidades, como Rio de Janeiro, Parintins e Paris. Quando

Poiésis, Niterói, v. 20, n. 33, jan./jun. 2019. 
instalado em locais com grande concentração de pessoas em situação de rua, como o Centro do Rio de Janeiro, Dormindo comumente é destruído, pois causa incômodo ao evidenciar uma questão problemática da cidade que costuma ser silenciada. Já em locais como Parintins, município do Amazonas onde não há forte presença de pessoas em situação de rua, a imagem do artista dormindo no chão é confundida com a imagem de um bêbado, que tem casa, mas não consegue chegar nela por conta de sua embriaguez e, consequentemente, dorme na rua. Esta situação é mais condizente com a cidade, como relata o artista:

\section{Por exemplo, São Sebastião do Coró-Coró, que fica no Amazonas, é um lugar onde não há mendigos, não há riqueza, mas também não há pobreza, há fartura de tudo. Eu colei lá essa figura dormindo, com as ga- linhas andando ao lado. Parecia que o cara havia acabado de cuidar das galinhas e estava lá dormindo, não havia essa conotação. Em Parintins, no Amazonas, onde não há gente em situação de rua, quando eu colei o Dormindo, cinco minutos depois apareceu uma garrafa de cachaça ao lado, porque o cara dormin- do na rua lá é o bêbado que não consegue chegar em casa. Mas quando eu coloco aqui no Rio, no Centro, a galera vai lá e arranca, porque incomoda. (FERRAZapud FERNANDES, 2017, p. 73)}

A partir do exemplo de Guga Ferraz, vemos como a cultura local determina a leitura sobre um trabalho artístico e poderíamos questionar se Tridente de Vogler causaria a mesma perturbação se instalado em outra região. Dormindo, na cidade do Rio de Janeiro, afirma a existência de pessoas que são marginalizadas e invisibilizadas, além de colocar em debate um sério problema habitacional na cidade. Mas é preferível rasgar aquela imagem a assumir que ela reflete a realidade. A imagem, entendida segundo as ideias de Hans Belting (2005) como aquilo que torna uma ausência visível ao transformá-la em uma nova forma de presença, causa mais incômodo do que aquilo que representa. A mesma questão se apresenta em outra intervenção de Guga Ferraz: Ônibus Incendiado (2003), que consiste na colagem de adesivos vermelhos, em formato de chamas, sobre placas de sinalização de pontos de ônibus. O artista desejava, a partir do seu trabalho, chamar atenção para os recorrentes casos de incêndios a ônibus no Rio de Janeiro que ocorriam em 2003. Apropriando-se de uma placa que sinaliza que aquele lugar é onde os ônibus realizam suas paradas, o artista, como um vírus, altera sua mensagem e a placa passa a co- 


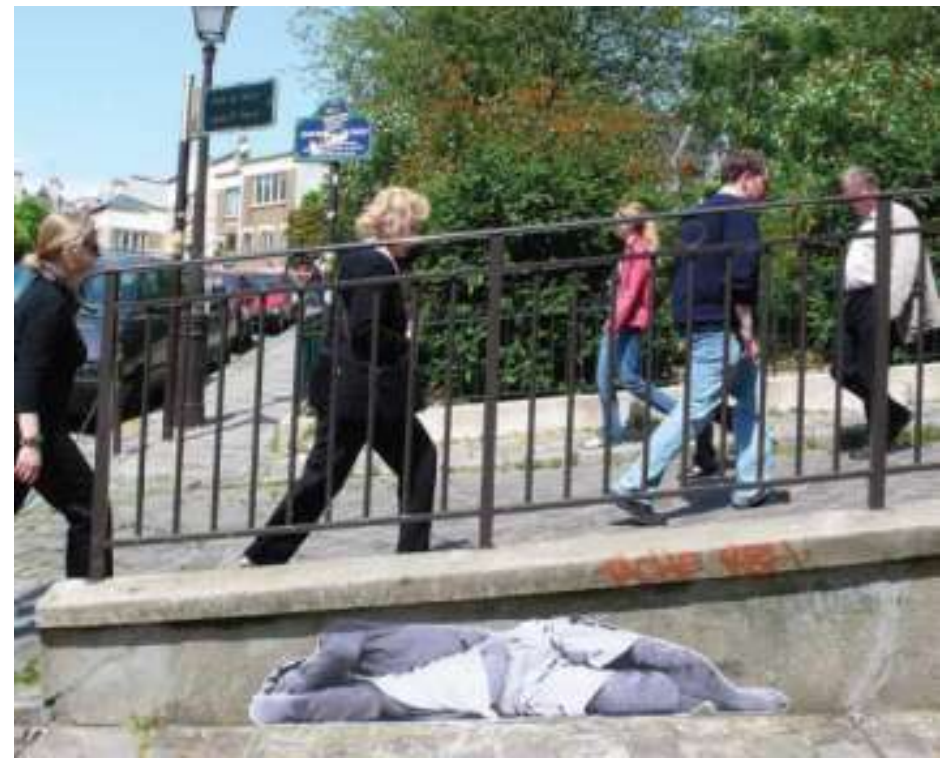

Fig. 3 - Guga Ferraz, Dormindo em Paris, 2007

cartaz lambe-lambe, impressão serigráfica

(Fonte: arquivo do artista)

Poiésis, Niterói, v. 20, n. 33, jan./jun. 2019. 


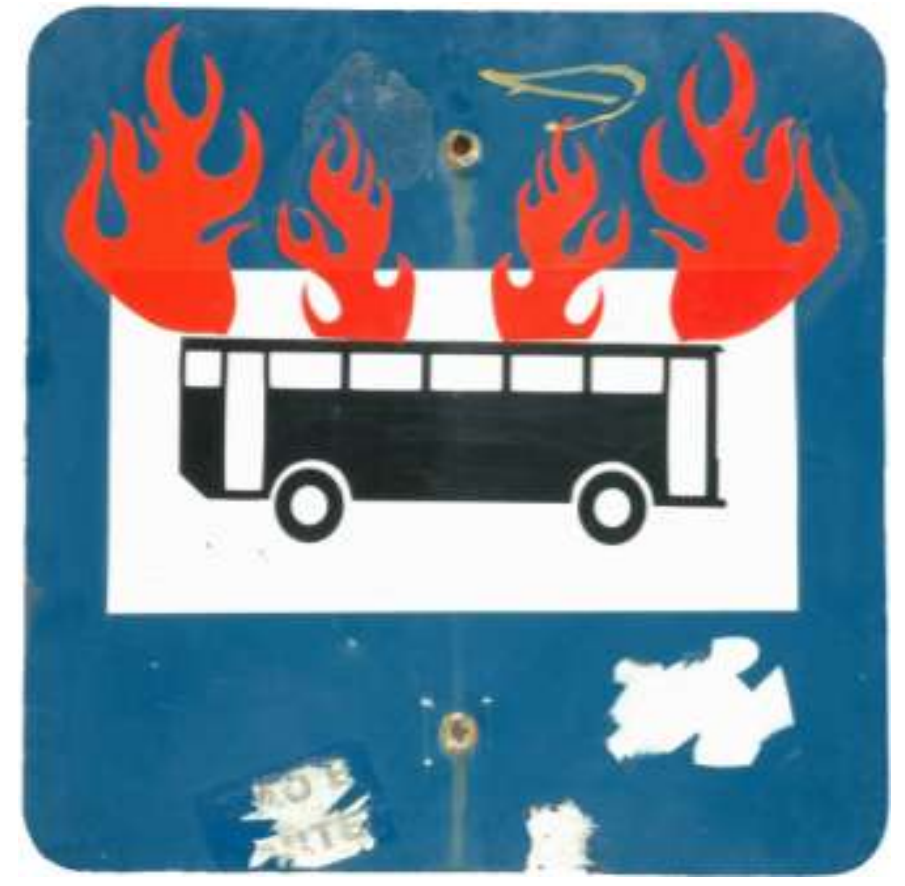

Fig. 4 - Guga Ferraz, Ônibus incendiado, 2003

intervenção com adesivo sobre sinalização urbana

(Fonte: arquivo do artista)

Poiésis, Niterói, v. 20, n. 33, jan./jun. 2018. 
municar que os veículos estão sendo incendiados. Esse trabalho, contudo, foi interpretado pelas autoridades locais como apologia ao crime, e em 2006 o então chefe da Polícia Civil do Rio de Janeiro ameaçou investigar a vida de Guga Ferraz.

\section{A Polícia Civil do Rio de Janeiro investigará se as intervenções feitas em placas de sinalização de pontos de ônibus, realizadas pelo artista Guga Ferraz, configuram crime de danificação de patrimônio público ou apologia ao crime. Guga colou adesivos, nas placas, que simbolizam um ônibus pegando fogo, sem auto- rização da prefeitura. \\ "As placas são patrimônio público, é preciso autorização da prefeitura para alterá-las. Vamos verificar se houve danificação do patrimônio, intenção de incitar um crime ou se foi simplesmente uma manifestação artística", afirmou o chefe da Polícia Civil, Ricardo Hallack. (TERRA, 11 de dezembro de 2016)}

Uma matéria da revista Época, publicada em abril de 2003, traça uma cronologia dos ataques ao Rio de Janeiro naquele ano. O texto mostra um cenário de guerra, com relatos de explosões de bombas e granadas, tiros, arrastões, fechamento de avenidas, mortes e incêndios de ônibus. Pelo menos 64 casos de ônibus incendiados são citados no texto, que trata apenas do período entre 24 de fevereiro e 9 de abril de 2003. O chefe da Polícia Civil, em seu depoimento para a mídia, utiliza o discurso da preservação do patrimônio público para se posicionar contra o trabalho artístico. Afirma preocupar-se com a placa de ônibus, um objeto banal, enquanto o verdadeiro patrimônio, a cidade, sofre diariamente com incêndios, tiroteios, explosões e assassinatos. Ironicamente, dois anos após ameaçar investigar a vida de Guga Ferraz para descobrir algum envolvimento com o crime, o então ex-chefe da Polícia Civil foi preso por possuir envolvimento com o crime. Por meio do choque e da repercussão ocasionadas pelo incêndio simbólico de placas de ônibus, o artista colocou em evidência a hipocrisia dos discursos das autoridades e da sociedade, que fecham os olhos diante da barbárie real e condenam uma ação da esfera artística. A condenação do trabalho artístico foi justificada nos jornais com depoimentos de pessoas que afirmavam que o trabalho de Guga Ferraz poderia incentivar outras pessoas a cometerem aquele crime contra os veículos. Tais discursos colocam em questão novamente o potencial que é atribuído às imagens no ato iconoclástico, quando ela, segundo Marie José-

Poiésis, Niterói, v. 20, n. 33, jan./jun. 2019. 
Mondzain (2009), além de acusada de fazer ver, doravante é acusada de "fazer fazer". Segundo essa hipótese, a força da imagem nos levaria a imitar seu conteúdo narrativo e exerceria violência na medida em que nos faz fazer. Tal foi a lógica assumida pelo presidente norte-americano após os ataques de 11 de setembro de 2001, quando anunciou um jejum das imagens: cenas de mortes, combates e violência foram censuradas, pois o atentado haveria sido prefigurado, ou mesmo inspirado, nos ecrãs hollywoodianos. A imagem foi colocada no banco de réus, acusada de originar tal barbárie. Tratada como um sujeito, a imagem é suspeita de poder abusar de sua potência.

Mas tal potência da imagem também é explorada por quem está no poder e toma para si o monopólio da imagem e sua significação. Mondzain (2016) afirma que todo poder tem suas imagens e recusa ao contra-poder ter sua visibilidade e, portanto, interrompe a busca icônica do outro. Basta lembrar da iconoclastia no período bizantino, quando o imperador, consciente do poder da imagem, privava dele a igreja e reservava para si sua exclusividade e benefícios. (MONDZAIN, 2013) Reações similares à imagem remontam a, pelo menos, o Antigo Egito, quando o faraó Tutmés III ordenou que destruíssem as estátuas de sua antecessora Hatchepsut como maneira de legitimar seu poder, ou ainda o exemplo do faraó Akhenaton, que quando chegou ao poder desafiou todo o sistema religioso do Antigo Egito ao substituir todo o panteão de deuses por uma única divindade - Atón, o deus Sol -, instaurando, desta maneira, o monoteísmo naquela civilização. Para obter êxito em tal objetivo, o faraó ordenou que fossem destruídas todas as imagens dos deuses antigos. Observamos, portanto, que em grande parte dos casos a iconoclastia é seletiva não culmina na destruição de todas as imagens, mas daquelas que apresentam algum risco para quem quer se manter no poder.

Tal questão é abordada também por Hans Belting no livro $A$ verdadeira imagem, onde o autor afirma que a imagem é, por natureza, representante vicária. As imagens representam instituições que dela se servem: "se a uma sociedade se impuserem imagens, esta vinga-se na primeira ocasião e vira-se contra os detentores do poder, que desfrutavam do poder de decisão sobre as imagens". (BELTING, 2011, p. 85) 
A iconoclastia imposta no século XVI, pela Reforma Protestante, se propaga até hoje em grupos evangélicos no Brasil, cuja doutrina rejeita o culto das imagens, defendendo que a fé deve ser associada somente às escrituras sagradas. Mas, paradoxalmente, seus líderes são donos de emissoras de TV e fazem uso de filmes, novelas e séries com temas bíblicos para propagar sua fé e impor seu poder. Assim como fazem uso da imagem televisiva para exibir atos iconoclastas, como o pastor de uma igreja neopentecostal que em 1995 chutou uma imagem de Nossa Senhora Aparecida em um canal aberto de TV, no dia da padroeira do Brasil católico. (FLÓRIDO, 2009) Trata-se de uma modalidade de iconoclastia praticada no contexto da cultura de massas que, paradoxalmente, se utiliza da imagem e seu valor de exposição para se difundir. Até mesmo a pichação, embora seja considerada vandalismo pela parcela mais conservadora da população, tem sido apropriada por grupos conservadores evangélicos para disseminar suas mensagens. Há alguns anos, têm sido vistos em muros do Rio de Janeiro as inscrições "Só Jesus expulsa demônios das pessoas", que também apresentam outras versões que ofendem diretamente religiões de matriz africana, como "Só Jesus expulsa Exu das pessoas". Tal alternância assinala a demonização da cultura afro-brasileira por grupos cristãos, bem como a relação entre Exu e Diabo presente nas leituras sobre o trabalho de Alexandre Vogler.

O caso de perseguição ao artista Wagner Schwartz, devido à performance La Bête, que integrou o $35^{\circ}$ Panorama da Arte Brasileira do Museu de Arte Moderna de São Paulo em 2017, apresenta bem as questões aqui levantadas. A presença de uma criança na sala e sua interação com o artista, que se apresentava nu e contava com a participação do público, levou grupos conservadores a acusarem o artista, a instituição e o curador de incentivarem a pedofilia. Um vídeo de um minuto, com um fragmento da performance de Schwartz (onde aparecia a criança), foi compartilhado massivamente por "iconoclastas" que, ironicamente, creem fielmente naquela imagem, que é descontextualizada e esvaziada de todo o seu conteúdo, ignorando mais de meio século de discussão sobre performance, sobre o corpo na arte, sobre os Bichos de Lygia Clark (que eram o mote do trabaIho performativo e interativo de Schwartz). Ignorou-se a exposição como um todo, seu contexto, seu recorte curatorial. No mesmo ano, a exposição QueerMuseu: cartografias da

Poiésis, Niterói, v. 20, n. 33, jan./jun. 2019. 


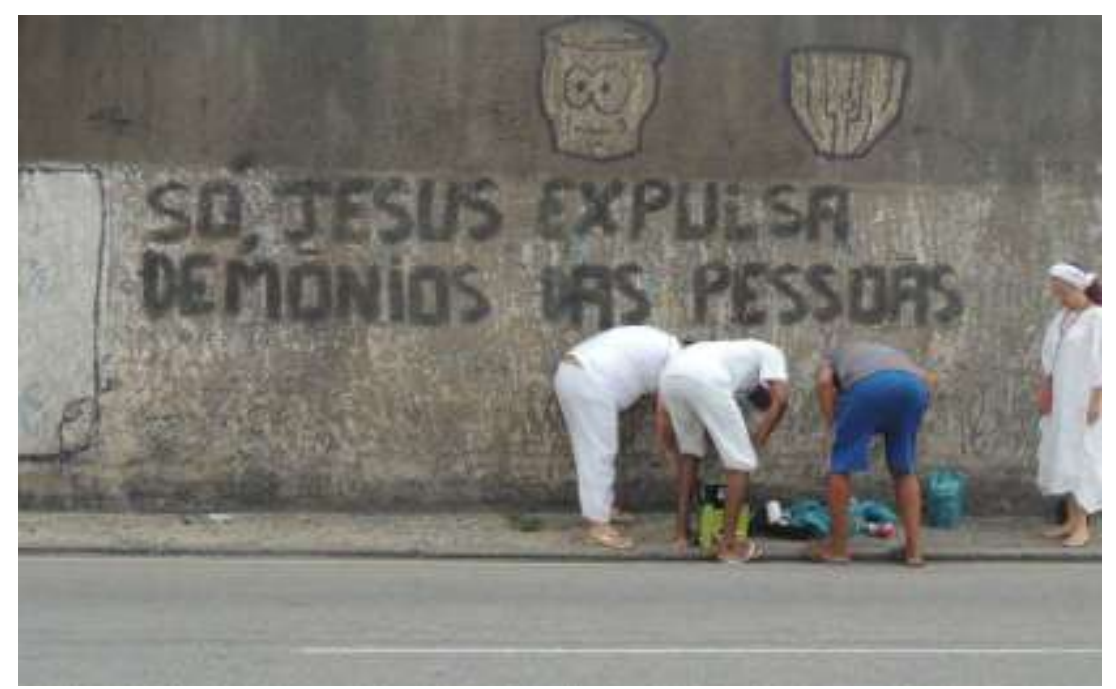

Fig. 5 - Candomblecistas apagam frases de intolerância religiosa em muros no Rio de Janeiro. (Fonte: Folha de São Paulo, 25/11/2015) 
diferença foi interditada por apresentar discussões sobre gênero e sexualidade, além de exibir trabalhos artísticos que flertam com o erotismo e se apropriam de signos religiosos. Grupos conservadores que sabotaram a exposição tiveram como principal plataforma as redes sociais para fazer circular fotografias e vídeos contaminados por discursos de ódio contra aquelas imagens que recusam e contra seus produtores.

Hans Belting (2011) afirma que o mundo não é a matriz para as imagens, mas as imagens tornaram-se matrizes do mundo. Ou seja, ao invés de se servir das imagens em função do mundo, passa-se a viver em função de imagens, fato que também é apontado pelo filósofo tcheco Vilém Flusser (1985) em sua Filosofia da caixa preta. O homem, segundo Flusser, esquece do motivo pelo qual as imagens são produzidas, a imaginação torna-se alucinação e há uma perda da capacidade de decifrar imagens.

Recusa-se a imagem do outro justamente por saber o poder que ela possui. O Tridente de Alexandre Vogler não cabe naquela "Cidade de Deus", como a caracteriza o prefeito. Embora signos do cristianismo estejam espalhados por diversos pontos de Nova Iguaçu, como a cruz instalada ao lado do tridente, os signos de outras religiões são recusados para que se mantenha a hegemonia do cristianismo, uma vez que a visibilidade do outro lhe dota de poder. Terreiros de Umbanda e de Candomblé, naquela mesma cidade, são frequentemente invadidos e depredados por aqueles que não creem nessas religiões e nas imagens lá presentes, mas, paradoxalmente, as destroem e, portanto, reconhecem sua potência. De maneira similar, a imagem de Guga Ferraz dormindo na rua e as placas com imagens de ônibus incendiados são destruídas por tornarem visível situações incômodas que não condizem com o slogan "Cidade Maravilhosa", referência comum à cidade do Rio de Janeiro.

A imagem, essa presença de uma ausência, sofre tentativas de destruição uma vez que aquilo que ela representa não pode ser aniquilado. Segundo Belting (2006), os iconoclastas queriam eliminar a imagem da imaginação coletiva. Imagens físicas eram atacadas para extinguir imagens mentais, pois acreditava-se que o que as pessoas não pudessem ver deixaria de existir em sua imaginação. Para os atuais iconoclastas, é mais fácil destru-

Poiésis, Niterói, v. 20, n. 33, jan./jun. 2019. 
ir imagens de um homem dormindo na rua e de um ônibus incendiado do que resolver os problemas habitacionais e de violência urbana. Assim como ocultar e demonizar um signo que remete à crença do outro, impedindo-o de ocupar um lugar de grande visibilidade como o Morro do Cruzeiro, que pode ser observado de diversos pontos de Nova Iguaçu é um meio de negar a existência ou o poder de outras religiões e afirmar a hegemonia de uma crença específica. Contudo, esses atos de negação e tentativas de destruição dotam as imagens de poder. Demonstram que, se devem ser destruídas, essas imagens possuem alguma força.

\section{Referências}

AMARO, Danielle Rodrigues. A cruz desconhecida pelos demônios. In Anais do $18^{\circ}$ Encontro Nacional da ANPAP/2009: Transversalidade nas Artes Visuais, 2009, Salvador, BA: EDUFBA, 2009, pp. 1683-1698.

BELTING, Hans. Por uma Antropologia da Imagem. Concinnitas, Rio de Janeiro (UERJ, DEART), ano 6, v. 1, n. 8, pp. 64-78, 2005.

BELTING, Hans. Imagem, Mídia e Corpo: uma nova abordagem à iconologia. Ghrebh, Revista de Comunicação, Cultura e Teoria da Mídia, São Paulo, n. 8, pp. 32-60, 2006.

BELTING, Hans. A verdadeira imagem. Porto: Dafne, 2011.

ÉPOCA. Cronologia dos ataques ao Rio de Janeiro. 09/04/2003. Disponível em http:// revistaepoca.globo.com/Epoca/0,6993,EPT515974-1664,00.html. Acesso em 13/04/2019.

FERNANDES, Thiago. Guga Ferraz: trânsitos entre espaço urbano e espaços expositivos. Monografia (Bacharelado em História da Arte). Rio de Janeiro: EBA/UFRJ, 2017. 
FLÓRIDO, Marisa. A Ambivalência da Imagem. Poiesis. Niterói, n. 13, pp. 31-44, 2009.

FLUSSER, Vilém. Filosofia da caixa preta. São Paulo: Hucitec, 1985.

JORNAL MEIA HORA. Prefeito de N. Iguaçu permite símbolo do inferno ao lado da cruz de Jesus Cristo. Rio de Janeiro, 15 de agosto de 2006.

JORNAL O DIA. Entre a cruz e o tridente. Rio de Janeiro, 15 de agosto de 2006.

JORNAL O DIA. Religiosos contra o tridente. Rio de Janeiro, 17 de agosto de 2006.

MITCHELL, W. J. T. O que as imagens realmente querem? In ALLOA, Emmanuel (Org.). Pensar a imagem. Belo Horizonte: Autêntica Editora, 2015.

MONDZAIN, Marie-José. A imagem pode matar? Lisboa: Vega, 2009.

MONDZAIN, Marie-José. Imagem, sujeito, poder. Outra Travessia: Revista de Literatura do PPGL/UFSC, Florianópolis, n. 22, pp. 175-192, 2016.

MONDZAIN, Marie-José. Imagem, ícone, economia: as fontes bizantinas do imaginário contemporâneo. Rio de Janeiro: Contraponto, 2013.

RANCIÈRE, Jacques. As imagens querem realmente viver? In ALLOA, Emmanuel (Org.). Pensar a imagem. Belo Horizonte: Autêntica Editora, 2015.

TERRA. Polícia investiga adesivos em pontos de ônibus. 11 de dezembro de 2006. Disponível em http://noticias.terra.com.br/brasil/noticias/0,,OI1294564-EI306,00-Policia+investiga+adesivos+em+pontos+de+onibus.html. Acesso em 13/04/2019. 